\title{
MAPPING PASTURE AREAS IN WESTERN REGION OF SÃO PAULO STATE, BRAZIL
}

\author{
A. F. C. Bonamigo ${ }^{1}$, J. de C. Oliveira ${ }^{1,1 *}$, R. A. C. Lamparelli ${ }^{2}$, G. K. D. A. Figueiredo ${ }^{1}$, E. E. Campbell ${ }^{3}$, J. R. Soares ${ }^{1}$, \\ L. A. Monteiro ${ }^{1}$, M. Vianna ${ }^{4}$, D. Jaiswal ${ }^{5}$, J. J. Sheehan ${ }^{6}$, L. R. Lynd ${ }^{7}$ \\ ${ }^{1}$ University of Campinas, School of Agricultural Engineering, São Paulo (FEAGRI), Brazil, (anaflaviabonamigo, juliannecoliveira, \\ johnnyrsoares, monteiroleonardo6)@gmail.com, gleyce.figueiredo@feagri.unicamp.br \\ ${ }^{2}$ University of Campinas, Interdisciplinary Center of Energy Planning (NIPE), São Paulo, Brazil - lamparel@g.unicamp.br \\ ${ }^{3}$ University of New Hampshire, New Hampshire, USA - elelcampbell@ gmail.com \\ ${ }^{4}$ University of Leeds, School of Earth and Environment, Leeds, United Kingdom - murilodsv@ gmail.com \\ ${ }^{5}$ Carl R.Woese Institute for Genomic Biology, University of Illinois, Illinois, USA - djaiswal@illinois.edu \\ ${ }^{6}$ Colorado State University, Colorado, USA - john.sheehan@ colostate.edu \\ ${ }^{7}$ Dartmouth College, New Hampshire, USA - lee.r.lynd@ dartmouth.edu
}

\section{KEY WORDS: Grasslands, Land Cover, Intensification, Classification, TWDTW, MODIS}

\begin{abstract}
Brazil is one of the largest exporters of cattle meat production. Most of this production is under pasture areas, with different levels of livestock and field management. Remotely sensed images could be interesting tools to detect distinct temporal and spatial patterns of these systems. In this context, classification algorithms have been proposed to use information from satellite images to map different land covers. The Time-Weighted Dynamic Time Warping (TWDTW) is an algorithm that has the advantage of working well with datasets with enough amounts of temporal information and seasonality patterns. In the present work, the TWDTW was performed to classify pasture managements in farms located in Western region of São Paulo State in Brazil for the years 2017 and 2018, as a primary study. It was used Normalized Difference Vegetation Index (NDVI) time series images from Moderate Resolution Imaging Spectroradiometer - MODIS sensor (products MOD13Q1 and MYD13Q) with 250 meters of spatial resolution. In classifications for the years 2017 and 2018, it was observed a predominance of traditional pasture. Total areas of degraded and traditional pasture were very similar between 2017 and 2018. The year of 2017 showed higher spatial distribution of intensified pastures than year 2018. The classification achieved satisfying results with complete accuracy in validation. The information collected from field visits were important to analyse general aspects of the results. Therefore, in this pilot study TWDTW algorithm demonstrated to have potential in differentiating classes of pasture management. Next steps will be to explore the possibilities to classify pasture systems in large areas.
\end{abstract}

\section{INTRODUCTION}

Latin America and the Caribbean contribute more than a quarter of all the world production of beef and poultry (FAO, 2018). In the region, the sector has grown at an annual rate of $3.7 \%$, a figure much higher than the average global growth rate $(2.1 \%)$. In this context, Brazil is the largest exporter of cattle meat production, producing about 9.9 millions of tonnes in 2018 (USDA, 2019), and most of these livestock production in Brazil are under pasture area.

An important premise for the increase in livestock productivity is the improvement of pastures in terms of quality and reverting degradation process, which is the main cause of quality loss in tropical countries (Aguiar et al., 2017). Monitoring pasture areas and management over time and space, such as intensification and degradation processes are essential to analyse and address livestock productivity and potential.

In context of monitoring pasturelands, remote sensing provides temporal and spatial patterns of ecosystem change and has been used to estimate biophysical characteristics of managed areas (Numata et al., 2007). A variety of classification methods have been proposed and used to map land cover using remotely sensed data (Rodriguez-Galiano et al., 2012), and each of those methods work better with certain characteristics of the remotely sensed dataset.

The Time-Weighted Dynamic Time Warping (TWDTW) is a classification method proposed by Maus et al. (2016). This algorithm takes in count the vegetation index time series from each pixel, where the temporal information is the key for differentiating one location from another and then classifying the pixels, since they can have different dynamics over time. The TWDTW algorithm works with the principle of comparison and alignment of a pre-established pattern and a pixel of the image time series; and calculate the distance between them (dissimilarity) to classify that pixel based on the lowest dissimilarity. This algorithm is derived from Dynamic Time Warping (DTW) algorithm (Giorgino, 2009), differentiating itself by using a penalizing function for the distance in days from the original period that the patterns were set, i.e., the TWDTW takes in count the specific dates when the patterns occur for the dissimilarity measure. Maus et al. (2016) describes that this function is useful for time series derived from agriculture and crops temporal patterns, because each crop has distinct phenological cycle and, therefore, the weighting function is useful to distinguish between these cycles. Since the TWDTW algorithm works mainly with temporal information, it has been proved to be useful in datasets with enough amount of temporal data, and scarce spatial information (e.g., Belgiu, Csillik, 2018).

The objective of the present work was to apply the TWDTW algorithm to classify Normalized Difference Vegetation Index (NDVI) from Moderate Resolution Imaging Spectroradiometer - MODIS images time series of pasture land cover areas under different levels of livestock and field management.

\footnotetext{
$1 *$ Corresponding author
} 


\section{MATERIAL AND METHODS}

\subsection{Study Area}

The study area comprehends four farms of cattle production located on Western Region of São Paulo State (Figure 1).

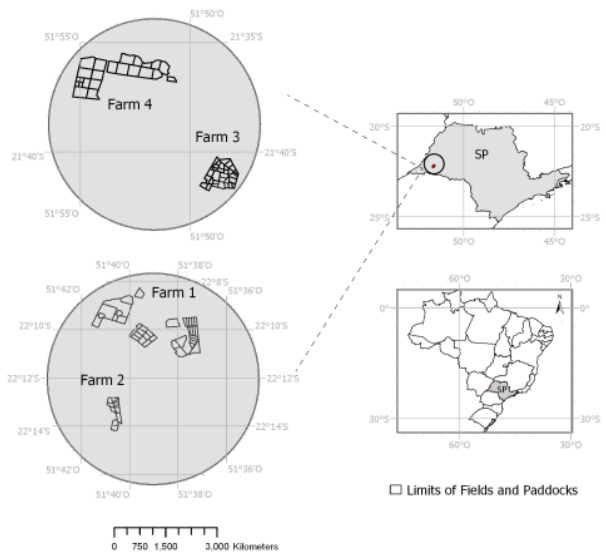

Figure 1. Location of study area with the farms visited

The four farms were visited in the period of August 2017 to November 2018 to collect information about the fields and paddocks managements that had been made in each location. In those visits, it was collected information about productivity, animal rotation dynamics in paddocks, and also the period of the year that it was used some intensification system. Farm 1 has fields with traditional management and intermediate productivity, being two of them with animal rotation, and three fields with intensification system (soybean and pasture) that was implemented in November 2016. Farm 2 has fields with degraded pasture, which have low productivity and exposed soil, and also fields with traditional management. Farm 3 has fields with traditional management, that have low to intermediate productivity, and also fields with degraded pasture. Farm 4 has fields with traditional management, using animal rotation in some of the fields, and also intensification system in one field.

With information about the four farms, the managements were defined in three main classes, "Degraded", "Traditional", and "Intensified", due to the different types of pasture biomass dynamics each of those classes present over time. The three classes and their respective definition are described in table 1.

From the study area, it was selected locations that represented the three different types of pasture and cattle management, and those locations were used as reference for performing the classification. It was selected two locations of degraded pasture in farm 3, two locations of intensified pasture in farm 1 , and thirteen locations with traditional pasture management in farms 1 and 2 .

\begin{tabular}{ccc}
\hline $\begin{array}{c}\text { Pasture } \\
\text { class }\end{array}$ & Definition of the class & $\begin{array}{c}\text { Number of areas } \\
\text { and points } \\
\text { visited }\end{array}$ \\
\hline Degraded & $\begin{array}{c}\text { Pasture with low } \\
\text { productivity, with signs of } \\
\text { degradation }\end{array}$ & 2 \\
Traditional & $\begin{array}{c}\text { Low to intermediate } \\
\text { productivity and animal } \\
\text { rotation }\end{array}$ & 13 \\
Intensified & $\begin{array}{c}\text { Intermediate to high } \\
\text { productivity, using } \\
\text { integration system with } \\
\text { soybean and pasture }\end{array}$ \\
\hline
\end{tabular}

Table 1. Field areas and points visited in each pasture class

\subsection{Satellite data}

Satellite imaging products were used in order to describe spatial-temporal behaviour of the three types of pasture management. The locations selected correspond to pixels of Normalized Difference Vegetation Index (NDVI) from Moderate Resolution Imaging Spectroradiometer - MODIS sensor (products MOD13Q1 and MYD13Q1 from Terra and Aqua platforms, collection 6). These products have 250 meters of spatial resolution and 16 days of temporal resolution, with a lag of 8 days between the two platforms. The period acquired was September 2016 to January 2019, and for the study area it was built a time series of 111 images of NDVI.

The NDVI is a vegetation index based on the normalized ratio between the near infrared (NIR, 700 to $1300 \mathrm{~nm}$ ) and red $(650$ $\mathrm{nm}$ ) bands. These two bands have different reflectance behavior in vegetation, where the absorption in red band is associated to the amount of chlorophyll, and the high reflectance in NIR band is associated with leaves structure. The NDVI is associated with the absolute amount of biomass and a vegetation measure that is sufficiently stable to permit comparisons of seasonal and inter-annual changes in vegetation growth and activity (Huete et al., 2002). Therefore, since different pasture management have distinct levels of biomass over time, the available NDVI products from MODIS sensor could represent a reliable indicator of the pasture systems.

The NDVI products from MODIS sensor have quality indexes associated to each pixel, indicating pixels poorly produced due to cloud presence. As a pre-processing, it was performed a prefiltering step, where the quality images were used to remove the pixels flagged as cloudy from each of the time series images. The indexes used for pre-filtering were "Pixel Reliability" and "Vegetation Index Quality". The pixels which values were removed were interpolated linearly with the previous and next images pixels values to obtain a complete pre-filtered time series. After the pre-filtering process, the time series were then filtered with the Savitzky-Golay (SG) smoothing filter. The filter used polynomial interpolation of third degree and interpolation window of 7 points. Figure 2 shows an example of an original and pre-filtered + smoothed NDVI time series of one field with pasture intensification (pasture + crop) in Farm 1.

In order to obtain a more accurate decision from the classifier, after the pre-filtering and filtering of the time series images it was applied a mask corresponding to pasture and annual crop maps from the MapBiomas Project (Projeto MapBiomas, 2017) for the year 2017. 


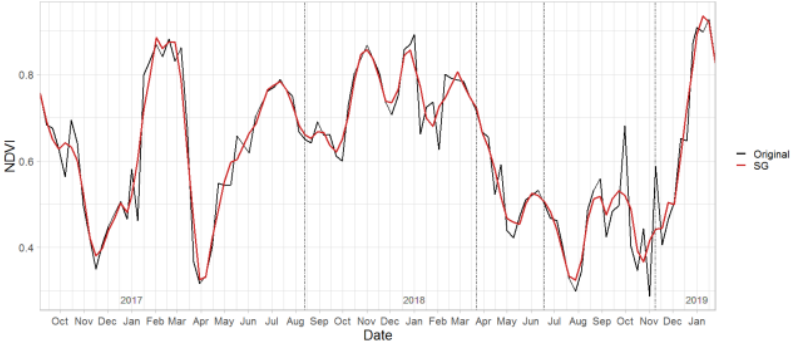

Figure 2. Example of original (black line) and smoothed NDVI time series using Savitzky-Golay filter (red line) of one field with pasture intensification.

\subsection{Classification}

The TWDTW algorithm used for land cover classification was performed in $\mathrm{R}$ programming language, with the package "dtwSat" (Maus et al., 2019). The algorithm uses three main entries: it should be provided the coordinates of a certain pixel (latitude and longitude), its respective label, and the time series period where a certain curve pattern occurs. As entries in the algorithm for the present work, 17 pasture locations were provided, containing the three labels of management.

With the temporal information provided about each label, the algorithm uses the subset of training locations for building temporal patterns for each label. In the present work, it was used 50\% of the points from each label for training set, and the spline function for smoothing the pattern curves for each label, with number of knots equal to $20(\mathrm{k}=20)$. The curves patterns created are presented in Figure 3.

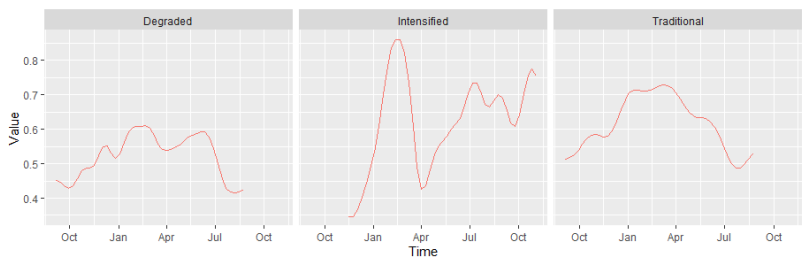

Figure 3. Temporal NDVI patterns of the three pasture managements described in Table 1 and used to classify the pasture areas of the study region

The TWDTW algorithm computes the dissimilarity between two time series, i.e., the dissimilarity between the pixels time series from the study area and each of the constructed patterns. The time-weighted dissimilarity uses a function for penalizing this measure that occurs in certain distance from the original patterns dates. In this work, it was used a logistic function with coefficients $\alpha=-0.1$ and $\beta=100$. After computing the dissimilarity values, the pixel is classified with the label from which pattern had the lower dissimilarity value.

Since the algorithm splits and then classifies the time series yearly, the complete time series was classified in two periods, where the first correspond to the period of 2017 (from September of 2016 to September 2017) and the second to the period of 2018 (from September 2017 to September 2018).

\subsection{Validation}

The complete dataset of locations was divided in $50 \%$ to training set and $50 \%$ to validation set. The algorithm divides the training and validation set per class, so that it could be assured that all classes have a validation set of locations. The number of locations used for training the algorithm and construct the time patterns, and for the validation are in Table 2 .

\begin{tabular}{ccc}
\hline Class & Train & Validation \\
\hline Degraded & 1 & 1 \\
Intensified & 1 & 1 \\
Traditional & 7 & 6 \\
\hline
\end{tabular}

Table 2. Number of location assigned for train and validation

The algorithm evaluates the locations designated for validation according to the classification year when the pattern from that pixel was first assigned. For example, if a pixel was first labeled as "Traditional" and the pattern was set from July 2018 to November 2018, and used in the validation set, then that location is validated only in the classification of 2018, even when there are more years classified by the algorithm. Therefore, the validation is performed in all the periods (years) classified, and the evaluation of the pixel is made in its designated classification year.

The total area inside the farms was account based on the total pixels from each class and each period of classification.

\section{RESULTS AND DISCUSSION}

One example of the distance matrix used to generate the pasture maps is shown in Figure 4. This distance matrix was used to classify the pasture areas for the class "Traditional" in the period of year 2017. We can observe that the levels of similarity between pixels occurred from pixels with lower distance values - more similar with class "Traditional" - to pixels with higher distance values - more dissimilar with class "Traditional". The land cover maps of pasture areas were generated based on the results of the distance matrix in each class and period of analysis.

Figure 5 shows the spatial distribution of the pasture managements over the region of the four farms visited for the periods of year 2017 and 2018 . We can observe a predominance of traditional pasture in the study area, mainly over the region of Farms 1 and 2 (Fig. 5 - upper part). The region over Farm 4 (Fig. 5 - middle part) shows the higher presence of intensified pastures. In contrast, the region of Farm 3 has a majority of degraded pasture (Fig. 5 - bottom part).

In general, considering the period of analysis, the year 2017 showed higher spatial distribution of intensified pastures than year 2018. These land cover changes were mainly from intensified to traditional pastures areas. Some examples can be observed in some fields of Farms 1, 2 and 4. In year 2018, traditional pastures also appear to replace some degraded pasture areas that occurred in year 2017. However, considering the fields limits in each farm, it can be observed an increase in areas with degraded pasture.

The confusion matrix resulted from the classification process did not show error during the validation, which means that all the samples used to validate the pasture classes were classified correctly in the respective classes.

The total areas of the pasture classes in each year and farm is presented in Table 3. Farm 4 showed the highest area with intensified pasture, much higher than other farms; about 9 times the farm with the second higher area in year 2017 (Farm 1) and 4 times higher in year 2018. It highlights the decrease of intensified pasture areas from year 2017 to 2018. In year 2018, 
only Farms 1 and 4 presented intensified pasture areas. Farm 3 did not show this pasture class in any period of analysis. In contrast, Farm 3 presented the highest degraded pasture area during all period, with a short increase between years (about $37.5 \mathrm{ha})$.

Considering the total area for each class in the two years, the classification for degraded and traditional pasture was more equal in terms of total area between 2017 and 2018, while the total area of intensified pasture had a decrease of almost 4 times from 2017 to 2018. The stability in degraded and traditional pasture areas was observed in all farms. The decrease of intensified areas occurred mainly in Farm 4 which was the farm with largest intensified area.
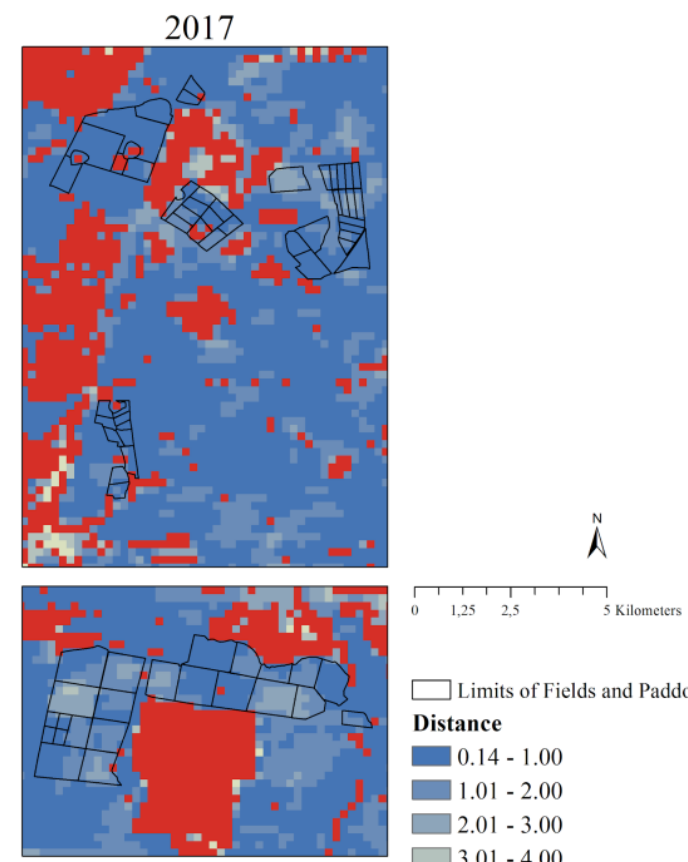

$\square$ Limits of Fields and Paddocks

Distance

$0.14-1.00$

$1.01-2.00$

$\square 2.01-3.00$

$\square 3.01-4.00$

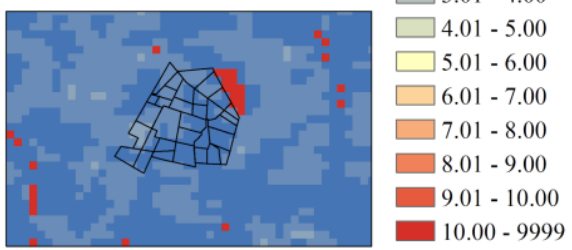

Figure 4. Example of distance matrix for year 2017, over the region of the four farms visited - upper: Farms 1 and 2; middle: Farm 4; and bottom: Farm 3
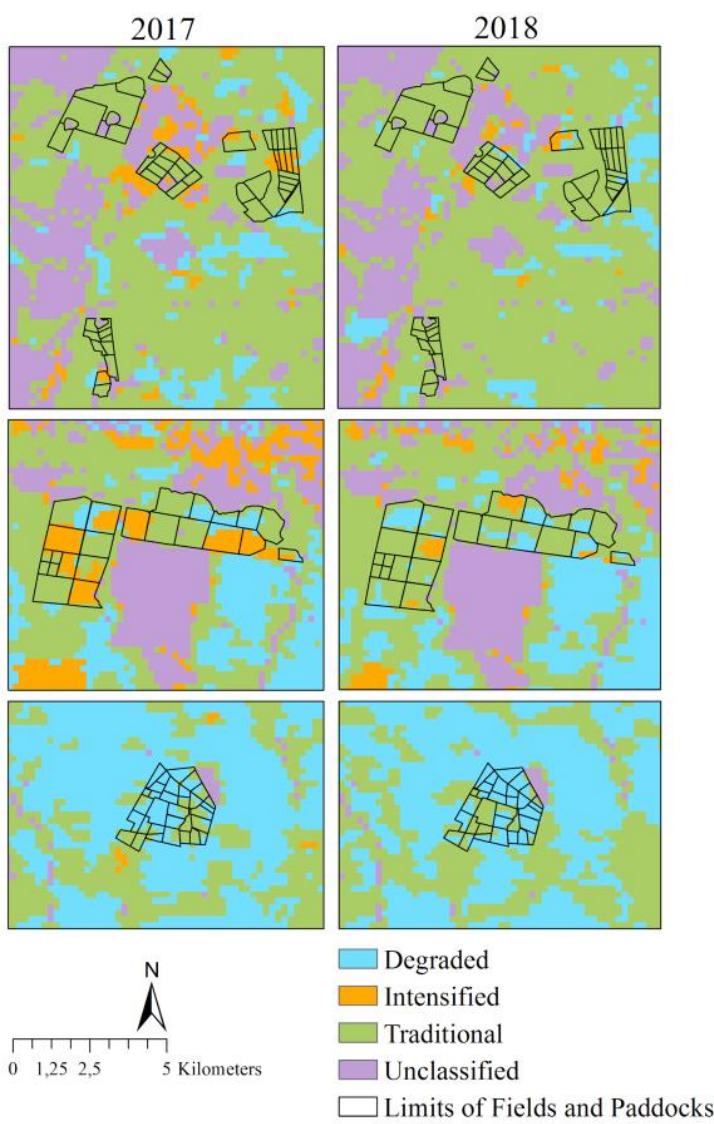

Figure 5. Land cover maps generated using the TWDTW classification method for the period of year 2017 (left) and 2018 (right) over the region of the four farms visited - upper: Farms 1 and 2; middle: Farm 4; and bottom: Farm 3. Unclassified regions represent the areas outside pasture and annual crops mask from the MapBiomas mapping Project for year 2017

\begin{tabular}{ccccccc}
\hline \multicolumn{7}{c}{ Area (ha) } \\
\hline Farm & \multicolumn{2}{c}{ Intensified } & \multicolumn{2}{c}{ Degraded } & \multicolumn{2}{c}{ Traditional } \\
& 2017 & 2018 & 2017 & 2018 & 2017 & 2018 \\
\hline 1 & 87.5 & 37.5 & 25.0 & 62.5 & 1362.5 & 1375.0 \\
2 & 18.7 & 0.0 & 0.0 & 0.0 & 181.2 & 200.0 \\
3 & 0.0 & 0.0 & 543.7 & 581.2 & 306.2 & 268.7 \\
4 & 775.0 & 150.0 & 306.2 & 437.5 & 1181.2 & 1675.0 \\
\hline Total & 881.2 & 187.5 & 874.9 & 912.4 & 3031.1 & 3518.7 \\
\hline
\end{tabular}

Table 3. Total pasture areas of each class in the four farms in 2017 and 2018 periods

\subsection{Discussion}

The distance matrix contains important information about the performance of the classification, as shown in Figure 4. If the absolute values of distance are very high, we could expect that the patterns set for calculating the dissimilarities for the classes are not in fact representing the behaviors presented in the area. For example, the low distance for traditional pasture in Farms 1 and 2, that in fact have fields with traditional pasture, reinforce the representative behavior of this pattern for the study area.

From the distance matrix, it could be provided also information about the variability of behavior present in the area, where two areas with the same category of management could have a slightly different temporal behavior of biomass in time or different spectral response, due to variations in the management. 
Bégué et al. (2018) reported different spectral responses between "continuous grazing" and "rotational grazing", where here we consider as the same class "Traditional". In studies with pasture areas using time series of satellite images, these different spectral responses could be analyzed using the absolute value of dissimilarity. Then, the classification could be improved by setting boundaries of distance values that could be used for labeling the pixels in the area, having a method that includes all variability inside the same class and allows to define subclasses.

One example of possible subclass derived from a pasture class is the traditional pasture that could be differentiated from traditional pasture that also has animal rotation between fields and paddocks over time. This class could be distinguished using the distance matrix to filter the traditional areas and then perform a second classification only in these pixels. Manabe et al. (2018) performed a two stage classification with TWDTW algorithm in crop-livestock systems and achieved interesting results for intensified pastures.

The pasture maps of the farms presented in Figure 5 showed a general tendency of more traditional and degraded pasture in over the years 2017 and 2018. The Western Region is historically an important livestock producer of the São Paulo State. In this region, traditional extensive management over the years contributed to degradation. According to Dias-Filho (2014), it is estimated that $50 \%$ to $70 \%$ of pastures areas in Brazil are under some level of degradation. The farm with the highest area of intensified pasture - a management that applies technology and increases the use of land - is considered a "model" in the region, for applying technified crop-livestock systems. However, it is not a reality in the region. The visible difference on amount of area implemented with the intensified system was evidenced in Table 3.

Farm 1 had most of its fields with traditional management. However, this farm started to implant intensified system in two fields since 2017, as it is shown in the map (Figure 5). In contrast, most of the areas in Farm 3 were classified as degraded pasture - about $50 \%$ of total area in both years (Table 3). It was known from field visits that Farm 3 is a family farming that has less resources and infrastructure. The limited resources to manage the forage contributed to the less capacity of the pasture to supporting animals, causing lower productivity. It could be also observed in Figure 5 that Farm 3 was surrounded by degraded pasture areas.

The total areas accounted for each class in the classification had different behaviors between 2017 and 2018. In Table 3, it could be seen the increase of degraded areas over the years and decrease of intensified pasture areas. The increase of degraded areas could be explained by different factors, such as increase of animal grazing in some areas, or the deficiency of water in periods of the year when the pasture was recovering. However, among many reasons that led to increase the areas classified as degraded, that change of class not necessarily mean that some areas continues permanently with low biomass. An example is Farm 4, where some areas in the northern fields classified in 2017 as traditional pastures and in 2018 as degraded could be influenced by some factor in a specific period, like high animal density, that led to low forage biomass. It highlights the importance of field campaigns to understand and discriminate the several land uses under pasture systems.

The decrease of intensified pasture areas from 2017 to 2018 could be also explained by the large amount of areas with crops planted as part of integration system. Areas where the pasture was restored by the end of 2017 and the crop implanted together with the restoration (e.g., grass + millet) could also be accounted as intensified system. From the field visits, it was known that in Farm 1 the field started an intensification with soybean in October 2017. In the same period, another field in Farm 4 was planted with an integrated system of pasture and millet. This field in Farm 1 classified as pasture intensification in 2017, was then classified as traditional in 2018, due to the fact it was remained pasture for two years and integrated with soybean again by the end of 2018 .

The achieved classification performance was satisfying, where the different pasture managements could be identified by the algorithm. The information previously collected from visits at the study areas were also important to analyse the general aspects and affirm that the classification was consistent with the areas were we had management information. The validation showed that the classification was completely accurate, which demonstrates the potential of TWDTW method for mapping pasture areas under different types of management. Nevertheless, this classification was performed in farm areas where the method could be test as pilot study. More sample points should be used and refinements are necessary to better define the managements and discriminate the patterns. Meanwhile, this methodology demonstrated potential to be extrapolated to larger areas.

\section{CONCLUSIONS}

The TWDTW algorithm demonstrated to be effective in identifying different pasture management, based on the behavior of those areas over time. The proportion of areas in each class and their changes between 2017 and 2018 showed consistency with the actual proportion of each management in pasture areas in Western region of São Paulo state. The validation showed that the algorithm could correctly classify different managements. This study pilot needs more refinement in some aspects, but demonstrated potential to be performed in larger areas.

\section{ACKNOWLEDGEMENTS}

This work was funded by the São Paulo Research Foundation (process numbers 2017/06037-4, 2016/08741-8, 2017/08970-0, 2018/11052-5, 2018/13295-2 and 2014/26767-9) as part of the Global Sustainable Bioenergy Initiative.

\section{REFERENCES}

Aguiar, D.A., Mello, M.P., Nogueira, S.F., Gonçalves, F.G., Adami, M., Theodor Rudorff, B.F., 2017. MODIS time series to detect anthropogenic interventions and degradation processes in tropical pasture. Remote Sens. 9, 1-20. https://doi.org/10.3390/rs9010073

Bégué, A., Arvor, D., Bellon, B., Betbeder, J., de Abelleyra, D., Ferraz, R.P.D., Lebourgeois, V., Lelong, C., Simões, M., Verón, S.R., 2018. Remote sensing and cropping practices: A review. Remote Sens. https://doi.org/10.3390/rs10010099

Belgiu, M., Csillik, O., 2018. Sentinel-2 cropland mapping using pixel-based and object-based time-weighted dynamic time warping analysis. Remote Sens. Environ. 204, 509-523. https://doi.org/10.1016/j.rse.2017.10.005 
Dias-Filho, M. B., 2014. Diagnóstico das Pastagens no Brasil. https://www.infoteca.cnptia.embrapa.br/bitstream/doc/986147/1 /DOC402.pdf. (29 November 2019)

FAO Regional Office for Latin America and the Caribbean, 2018. Livestock sector in Latin America and the Caribbean has great potential to mitigate its greenhouse gas emissions. http://www.fao.org/americas/noticias/ver/en/c/1150594/ (10 October 2019).

Giorgino, T., 2009. Computing and Visualizing Dynamic Time Warping Alignments in R : The dtw Package . J. Stat. Softw. 31. https://doi.org/10.18637/jss.v031.i07

Huete, A., Didan, K., Miura, T., Rodriguez, E.P., Gao, X., Ferreira, L.G., 2002. Overview of the radiometric and biophysical performance of the MODIS vegetation indices. Remote Sens. Environ. 83, 195-213. https://doi.org/10.1016/S0034-4257(02)00096-2.

Manabe, V.D., Melo, M.R.S., Rocha, J.V., 2018. Framework for mapping integrated crop-livestock systems in Mato Grosso, Brazil. Remote Sens. 10. https://doi.org/10.3390/rs10091322

Maus, V., CǍmara, G., Cartaxo, R., Sanchez, A., Ramos, F.M., De Queiroz, G.R., 2016. A Time-Weighted Dynamic Time Warping Method for Land-Use and Land-Cover Mapping. IEEE J. Sel. Top. Appl. Earth Obs. Remote Sens. 9, 3729-3739. https://doi.org/10.1109/JSTARS.2016.2517118

Maus, V., Câmara, G., Appel, M., Pebesma, E., 2019. dtwSat: Time-weighted dynamic time warping for satellite image time series analysis in R. J. Stat. Softw. 88. https://doi.org/10.18637/jss.v088.i05

Projeto MapBiomas, 2017. Coleção 4 - Série Anual de Mapas de Cobertura e Uso de Solo do Brasil. http://mapbiomas.org. (5 October 2019).

Numata, I., Roberts, D.A., Chadwick, O.A., Schimel, J., Sampaio, F.R., Leonidas, F.C., Soares, J. V., 2007. Characterization of pasture biophysical properties and the impact of grazing intensity using remotely sensed data. Remote Sens. Environ. 109, 314-327. https://doi.org/10.1016/j.rse.2007.01.013

Rodriguez-Galiano, V.F., Ghimire, B., Rogan, J., Chica-Olmo, M., Rigol-Sanchez, J.P., 2012. An assessment of the effectiveness of a random forest classifier for land-cover classification. ISPRS J. Photogramm. Remote Sens. 67, 93-104. https://doi.org/10.1016/j.isprsjprs.2011.11.002

USDA - United States Department of Agriculture, 2019. Livestock and poultry: world markets and trade. https://apps.fas.usda.gov/psdonline/circulars/livestock_poultry.p df. (15 August 2019) 